\title{
House dust mite-specific immunoglobulin E and longitudinal exhaled nitric oxide measurements in children with atopic asthma
}

\author{
Youn Kyung Lee, MD', Sohyoung Yang, MD', Joohyun Park, MD', Heon Kim, MD, PhD², Youn-Soo Hahn, MD, PhD' \\ Departments of ${ }^{1}$ Pediatrics and ${ }^{2}$ Preventive Medicine, Medical Research Institute, Chungbuk National University College of Medicine, Cheongju, Korea
}

Purpose: House dust mite (HDM) has been suggested to be the most important aeroallergen responsible for atopic asthma in Korea. We aimed to investigate that specific IgE antibodies to HDM and other common indoor aeroallergens contribute differently to total serum IgE and show different relationships with longitudinal fractional exhaled nitric oxide (FeNO) measurements in Korean atopic asthmatic patients.

Methods: A total of 193 children aged 8 to 16 years with intermittent or mild persistent atopic asthma were recruited. Sera were assayed for total IgE and specific IgE antibodies to HDM and other common indoor allergens. FeNO was serially measured 10 times or more over 2 years when subjects were not receiving controller medications.

Results: In 152 children who completed the study, IgE antibodies to specific HDM were more prevalent than those to other common indoor aeroallergens. In addition, IgE antibody titers to HDM were the strongest contributor to total lgE increases. Furthermore, only HDM-specific IgE antibody titer significantly correlated with maximum FeNO $(r=0.21, P=0.029)$ and the rate of FeNO higher than 21 parts per billion (ppb) $(r=0.30, P=0.002)$. Eight patients (5\%) were found to have maximum FeNO of $21 \mathrm{ppb}$ or less, suggesting the presence of a low FeNO phenotype among atopic asthmatic patients. Conclusion: The quantity of HDM-specific lgE antibody provides a possible explanation for increases of total lgE and significantly correlates with the amount and frequency of FeNO increases in Korean atopic asthmatic patients.

Key words: Allergens, Asthma, Child, Nitric oxide, Immunoglobulin E

\section{Introduction}

Allergen exposure is an important exacerbation trigger for a substantial proportion of asthmatic patients ${ }^{1}$. For this reason, the evaluation of aeroallergens including perennial indoor allergens is recommended for subjects with persistent asthma ${ }^{2,3)}$. In particular, asthma has been found to be more common in countries with high house dust mite (HDM) exposure $^{4,5)}$. In addition, in areas where asthma had been found to be more common, HDMspecific IgE antibody could make a major contribution to total serum IgE ${ }^{6,7)}$.

Fractional exhaled nitric oxide (FeNO) has been proposed as means of assessing airway inflammation. High FeNO values above certain cut-point may indicate active eosinophilic airway inflammation and the likelihood of deterioration in asthma control ${ }^{8)}$. However, longitudinal measurements of FeNO are required for the analysis of its efficacy in the monitoring of asthmatic patients because isolated FeNO measurements appear unsuccessful in capturing FeNO profiles due to the fluctuating nature of FeNO levels ${ }^{9-11}$. In addition, FeNO has been observed to be increased primarily in atopic asthma ${ }^{12-14)}$, implying that the
Corresponding author: Youn-Soo Hahn, MD, PhD Department of Pediatrics, Chungbuk National University College of Medicine, 410 Sunbong-ro, Heungdeok-gu, Cheongju 361-763, Korea Tel: +82-43-269 6042

Fax: +82-43-264 6620

E-mail: yshahn@chungbuk.ac.kr

Received: 27 August, 2014 Revised: 10 October, 2014 Accepted: 30 October, 2014

Copyright $(2015$ by The Korean Pediatric Society

This is an open-access article distributed under the terms of the Creative Commons Attribution NonCommercial License (http://creativecommons.org/ licenses/by-nc/3.0//) which permits unrestricted noncommercial use, distribution, and reproduction in any medium, provided the original work is properly cited. 
efficacy of FeNO is enhanced when analysis is performed in the population which includes only atopic individuals. Furthermore, inhaled corticosteroid (ICS)-induced decrease of FeNO levels ${ }^{15,16)}$ suggests that a more accurate evaluation of FeNO levels in asthmatic patients would be achieved if FeNO is measured after discontinuation of ICSs.

In previous studies of Korean allergic subjects, HDM has been suggested to be the predominant aeroallergen responsible for atopic asthma ${ }^{17)}$. On the basis of these findings, we have hypothesized that specific IgE antibodies to HDM and other common indoor aeroallergens show different relationships with FeNO levels in Korean atopic asthmatic patients. To test this hypothesis, we serially measured FeNO more than 10 times in atopic asthmatic patients when they were not receiving controller medications. After completion of measurements, we defined FeNO profiles for each patient and explored the relationship between FeNO measurements and the levels of IgE antibodies specific to allergens.

\section{Materials and methods}

\section{Subjects and study design}

We enrolled 193 children aged 8 to 16 years with intermittent or mild persistent asthma, who had been receiving care at the outpatient clinic of Chungbuk National University Hospital, Cheongju, Korea. All of the participants were found to be sensitized to more than 1 common indoor aeroallergen and previously diagnosed to have asthma based on documentation of airway hyperresponsiveness (provocative concentration of methacholine causing a 20\% fall in $\mathrm{FEV}_{1}$ [methacholine $\left.\mathrm{PC}_{20}\right] \leq 8 \mathrm{mg} / \mathrm{mL}$ ) and/or reversible airflow obstruction ( $\geq 12 \%$ improvement of forced expiratory volume in one second $\left[\mathrm{FEV}_{1}\right]$ in response to inhaled $\beta_{2}$-agonist). The enrolled individuals had 1-2 exacerbations during the previous 1 year. They had no other clinically significant conditions. Total serum IgE level, peripheral eosinophil counts, and serum eosinophil cationic protein (ECP) were obtained at baseline. The Ethics Committee of Chungbuk National University Hospital Institutional Review Board approved the study (CBNUH IRB No. 2010-12-078) and written informed consent was obtained from the parents of all subjects. The study was conducted in accordance with the Declaration of Helsinki.

The study took place between June, 2010, and May, 2013. FeNO was serially measured in all participants 10 times or more over 2 years. Lung function tests including maximum bronchodilator reversibility were performed at least 3 times during the last year of monitoring. In addition, participants had received annual methacholine provocation challenge tests. Participants had not received inhaled short-acting $\beta_{2}$-agonists in 8 hours prior to measurements and had not received regular treatment with controller medications for at least 1 month before spirometric and FeNO measurements. The minimal interval between each measurement was 1 month. During the course of the study, participants who maintained asthma control did not receive any medication even though their FeNO levels were thought to have increased. However, participants whose asthma became uncontrolled received twice daily treatment with ICS until asthma control was maintained. Reliever medication was used as needed to relieve asthma symptoms.

\section{FeNO measurement}

FeNO was measured by a nitric oxide (NO) analyzer with electrochemical sensors (NIOX MINO, Aerocrine AB, Solna, Sweden), according to the European Respiratory Society (ERS)/American Thoracic Society (ATS) guidelines ${ }^{18)}$ and expressed as parts per billion (ppb). The children were instructed to avoid eating and strenuous exercise in the 2 hours before FeNO measurements. After inhalation of ambient air through a NO scrubber to total lung capacity, subjects then exhaled at a constant flow rate of 50 $\mathrm{mL} / \mathrm{sec}$. Nasal clips were not used as these could affect closure of the soft palate, leading to NO contamination derived from the nasal cavity. The exhalation times were 6-10 seconds with a 2-minute analysis period. FeNO measurements were conducted twice and a third measurement was performed if there was a more than 10\% difference between first two measurements.

\section{Pulmonary function testing}

Lung function tests were performed with a spirometer (Vmax SensorMedics, Yorba Linda, CA, USA) in accordance with the ERS/ATS recommendations ${ }^{19)}$. Forced vital capacity (FVC), $\mathrm{FEV}_{1}$, and the $\mathrm{FEV}_{1} / \mathrm{FVC}$ ratio were obtained from the best of 3 reproducible forced expiratory maneuvers. The percent predicted values were calculated based on the Third National Health and Nutrition Examination Survey ${ }^{20)}$. Methacholine $\mathrm{PC}_{20}$ and maximum bronchodilator responses were measured in all participants in accordance with ERS/ATS guidelines ${ }^{19,21)}$. Methacholine was inhaled in doubling concentrations ranging from 0.05 to $16 \mathrm{mg} / \mathrm{mL}$ at 5-minute intervals according to a standardized procedure. $\mathrm{FEV}_{1}$ was measured after inhalation of methacholine by 2-minute tidal breathing through a calibrated nebulizer (model 646, Devilbiss Health Care Inc., Somerset, PA, USA). The methacholine $\mathrm{PC}_{20}$ was determined by performing the methacholine-inhalation challenge until the $\mathrm{FEV}_{1}$ decreased by at least $20 \%$ from the baseline $\mathrm{FEV}_{1}$. Salbutamol (400 $\mu \mathrm{g}$ ) was administered to determine bronchodilator response. Lung function was measured before and 10 minutes after the administration of salbutamol. 


\section{Assessment of allergic sensitization}

Serum samples were assayed for IgE to common indoor aeroallergens including HDM (Dermatophagoides pteronyssinus), Alternaria, dog, cat, and cockroach by using the ImmunoCAP system (Immunodiagnostics; Thermo Fisher Scientific, Uppsala, Sweden). IgE levels were considered positive at levels of $0.35 \mathrm{IU} /$ $\mathrm{mL}$ or more.

\section{Statistical analysis}

The demographic and clinical data for continuous variables are presented as the means and standard deviations. FeNO, IgE antibody levels, methacholine $\mathrm{PC}_{20}$ values, total eosinophil count, and ECP were logarithmically transformed to assume a normal distribution and expressed as a geometric means with the 95\% confidence intervals. Pearson correlation was used to analyze the correlation between specific IgE antibody titers and total IgE and the correlation between specific IgE antibody titers and FeNO measurements. Standardized coefficients were calculated by a multiple regression analysis model where both total IgE (outcome) and specific IgE titers (predictors) were log-transformed. The differences between patients with low and high FeNO groups were compared by using the Wilcoxon rank-sum test for continuous variables and Fisher exact test for the categorical ones. A $P$ value of $<0.05$ was considered significant. Statistical analyses were performed using a SAS 9.12 (SAS Institute Inc., Cary, NC, USA).

\section{Results}

\section{Patient characteristics}

Among the 193 patients with atopic asthma who were invited to participate in the study, 157 patients could be monitored over 2 years with FeNO measurements more than 10 times when they were not receiving controller medications. A total of 5 children declined study participation, and 152 children (118 boys) were

Table 1. Baseline characteristics of study participants

\begin{tabular}{lc}
\hline Characteristic & Value \\
\hline Age $(\mathrm{yr})$ & $11.9 \pm 2.9$ \\
Sex & \\
$\quad$ Male:female & $118: 34$ \\
Exposure to smoke, $\mathrm{n}(\%)$ & $54(35.5)$ \\
Body mass index $\left(\mathrm{kg} / \mathrm{m}^{2}\right)$ & $19.5 \pm 3.6$ \\
Total serum $\lg \mathrm{E}(\mathrm{IU} / \mathrm{mL})$ & $430(363-509)$ \\
ECP $(\mathrm{ng} / \mathrm{mL})$ & $26.2(22.7-30.2)$ \\
Total eosinophil count $(/ \mathrm{LL})$ & $341(295-395)$
\end{tabular}

Values are presented as mean \pm standard deviation or geometric mean $(95 \%$ confidence interval) unless otherwise indicated.

$\mathrm{SD}$, standard deviation; ECP, eosinophil cationic protein. therefore included in the final analysis. The baseline data for 152 children are presented in Table 1 . Among these subjects, specific IgE antibody to $D$. pteronyssinus was most common (Table 2). In addition, the titers of specific IgE antibody to HDM were higher than $17.5 \mathrm{IU} / \mathrm{mL}$ in more than half of the HDMsensitized children. In contrast, there were fewer children with IgE antibodies specific to Alternaria, cockroaches, dogs, or cats that were higher than $17.5 \mathrm{IU} / \mathrm{mL}$.

\section{Relationship between specific $\lg \mathrm{E}$ titers and total $\lg \mathrm{E}$}

We compared the quantitative relationships between specific IgE antibody to each indoor allergen and total IgE. The titers of specific IgE antibodies to D. pteronyssinus, Alternaria, and cockroach were significantly and positively correlated with total IgE, whereas those to dogs and cats were not. The strongest correlation was seen with $D$. pteronyssinus $(r=0.688, P<0.001)$ (Table 3). In addition, when the contribution of each specific IgE was evaluated using multiple regression analysis, the IgE antibody titers to $D$. pteronyssinus, Alternaria, and cockroaches were significantly associated with total IgE, which is in contrast to the IgE antibody titers specific to dogs and cats which were not associated with total IgE levels. In this analysis, the IgE antibody titer to $D$. pteronyssinus was also the strongest contributor to the increase of total IgE (standardized coefficient, 0.699; $P<0.001$ ).

\section{Distribution of patients according to FeNO profiles}

As shown in Fig. 1, all of the study participants were stratified into subgroups based on the maximum FeNO and the rate of

Table 2. Levels and prevalence of serum IgE specific to indoor aeroallergens among study participants

\begin{tabular}{lccccc}
\hline \multirow{2}{*}{ Allergen } & $\begin{array}{c}\text { Positive subjects, } \\
\mathrm{n}(\%)\end{array}$ & \multicolumn{4}{c}{$\begin{array}{c}\text { Distribution of subjects according to } \\
\text { Specific lgE levels (IU/mL) }\end{array}$} \\
\cline { 3 - 6 } & & $<17.5$ & $17.5-50$ & $51-100$ & $>100$ \\
\hline Der $p$ & $141(93.0)$ & 52 & 28 & 34 & 27 \\
Alternaria & $56(36.8)$ & 45 & 7 & 2 & 2 \\
Cockroach & $31(20.4)$ & 27 & 3 & 1 & 0 \\
Dog & $31(24.3)$ & 30 & 1 & 0 & 0 \\
Cat & $32(21.1)$ & 31 & 1 & 0 & 0 \\
\hline
\end{tabular}

Der $p$, Dermatophagoides pteronyssinus.

Table 3. Associations between allergen-specific IgE antibodies and total $\lg \mathrm{E}$

\begin{tabular}{lcrcr}
\hline Variable & $r$ & $P$ value & Standardized coefficients & $P$ value \\
\hline Der $p$ & 0.688 & $<0.001$ & 0.699 & $<0.001$ \\
Alternaria & 0.185 & 0.008 & 0.230 & $<0.001$ \\
Cockroach & 0.245 & $<0.001$ & 0.171 & 0.002 \\
Dog & 0.122 & 0.078 & 0.038 & 0.403 \\
Cat & 0.021 & 0.731 & -0.001 & 0.988
\end{tabular}

Der $p$, Dermatophagoides pteronyssinus. 

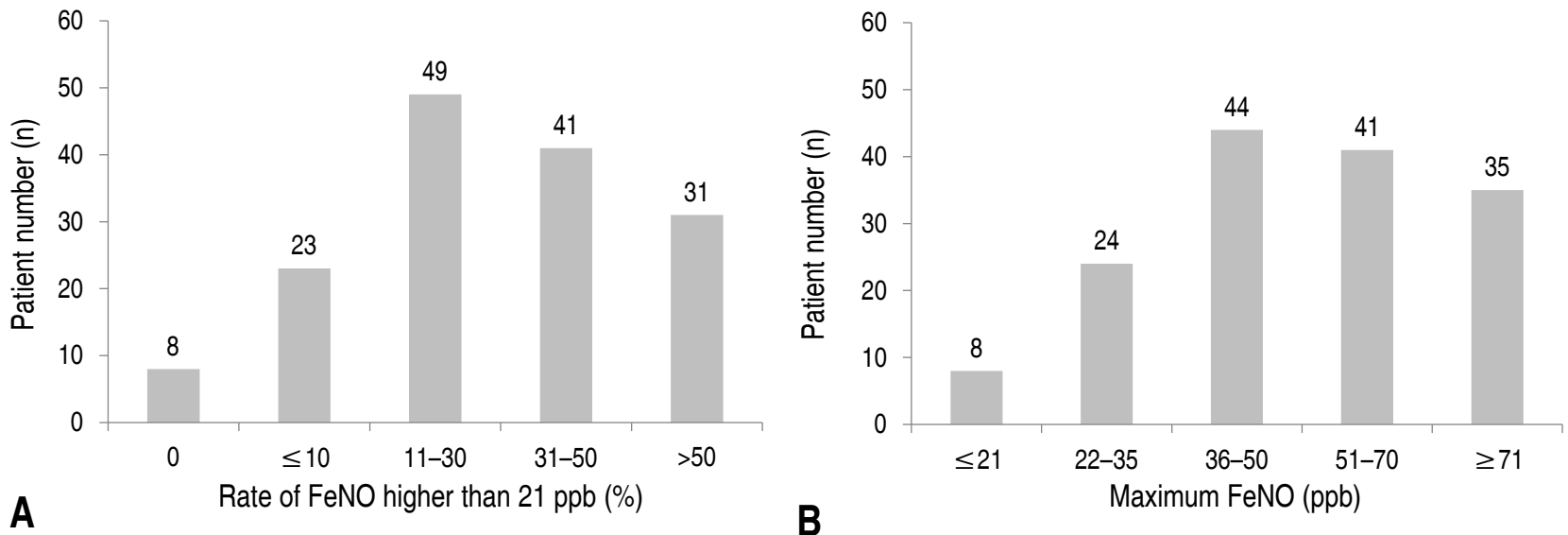

Fig. 1. Distribution of patients according to the rate of fractional exhale nitric oxide (FeNO) higher than 21 ppb (A) and maximum FeNO (B). ppb, parts per billion.

Table 4. Comparison between low and high fractional exhale nitric oxide phenotypes

\begin{tabular}{|c|c|c|c|}
\hline Variable & Low phenotype $(\mathrm{n}=8)$ & High phenotype $(n=144)$ & $P$ value \\
\hline Age (yr) & $10.7 \pm 3.2$ & $13.0 \pm 2.9$ & 0.161 \\
\hline \multicolumn{4}{|l|}{ Sex } \\
\hline Male:female & $4: 4$ & $104: 40$ & 0.189 \\
\hline Exposure to smoke, n (\%) & $5(62.5)$ & $58(40.3)$ & 0.214 \\
\hline Body mass index $\left(\mathrm{kg} / \mathrm{m}^{2}\right)$ & $19.8 \pm 3.1$ & $20.7 \pm 3.8$ & 0.401 \\
\hline Total serum lgE (IU/mL) & 337 (123-928) & $449(378-535)$ & 0.455 \\
\hline $\mathrm{ECP}(\mathrm{ng} / \mathrm{mL})$ & $23.4(11.7-46.8)$ & $27.2(23.4-31.7)$ & 0.947 \\
\hline Total eosinophil count $(/ \mu \mathrm{L})$ & 227 (70-741) & $368(318-427)$ & 0.308 \\
\hline Patients sensitized to Der $p, \mathrm{n}(\%)$ & $8(100)$ & $133(92.4)$ & 0.466 \\
\hline Level of Der $p$-specific lgE (IU/mL) & $11.2(2.1-60.7)$ & $21.9(15.8-30.2)$ & 0.224 \\
\hline Maximum FeNO (ppb) & $18.7(16.4-21.3)$ & $51.5(48.3-55.0)$ & $<0.001$ \\
\hline Methacholine $\mathrm{PC}_{20}(\mathrm{mg} / \mathrm{mL})$ & $1.89(0.64-5.55)$ & $1.64(1.27-2.11)$ & 0.964 \\
\hline $\operatorname{BDR}(\%)$ & $14.7 \pm 3.6$ & $13.8 \pm 8.2$ & 0.208 \\
\hline $\mathrm{FEV}_{1}(\%)$ & $77.4 \pm 21.3$ & $79.6 \pm 10.5$ & 0.865 \\
\hline $\mathrm{FEV}_{1} / \mathrm{FVC}(\%)$ & $75.4 \pm 10.7$ & $76.3 \pm 7.8$ & 0.813 \\
\hline
\end{tabular}

Values are presented as mean \pm standard deviation or geometric mean ( $95 \%$ confidence intervals) unless otherwise indicated.

ECP, eosinophil cationic protein; Der p, Dermatophagoides pteronyssinus; FeNO, fractional exhale nitric oxide; ppb, parts per billion; $\mathrm{PC}_{2,}$, provocative concentration of methacholine causing a $20 \%$ fall in $\mathrm{FEV}_{1}$; BDR, bronchodilator response; $\mathrm{FEV}_{1}$, forced expiratory volume in one second; FVC, forced vital capacity.

FeNO higher than $21 \mathrm{ppb}$. Maximum FeNO was higher than $35 \mathrm{ppb}$ in the majority of patients. Interestingly, while the maximum FeNO levels in most of patients were higher than 21 ppb, 8 patients had maximum FeNO of 21 ppb or less. Therefore, the rate of FeNO higher than $21 \mathrm{ppb}$ in these patients was $0 \%$, suggesting the presence of a low FeNO asthma phenotype among atopic asthmatic patients. All of these 8 patients were sensitized to $D$. pteronyssinus and their IgE antibody titers to HDM were not significantly different from those of patients with maximum FeNO of $21 \mathrm{ppb}$ or more. In addition, there were no differences in age, anthropometric values, and exposure to parental smoking, spirometric measurements, or atopic parameter such as total
IgE, ECP and eosinophil counts between the high and low FeNO phenotypes (Table 4).

\section{Relationship between specific IgE titers and FeNO}

The correlation of FeNO levels with titers of specific IgE antibody to indoor aeroallergens was assessed in two different ways in which we used maximum FeNO of the serial measurements and the rate of FeNO higher than $21 \mathrm{ppb}$ as the independent variables. There was a significant positive correlation between the titers of specific IgE antibody to $D$. pteronyssinus and maximum FeNO. Moreover, the titers of specific IgE antibody to $D$. pteronyssinus were found to be more strongly correlated 
Table 5. Correlation of allergen-specific $\lg E$ antibody titers with the rate of FeNO higher than $21 \mathrm{ppb}$ and maximum FeNO

\begin{tabular}{lcccc}
\hline \multirow{2}{*}{ Allergen } & \multicolumn{2}{c}{ Rates of FeNO $>21 \mathrm{ppb}$} & \multicolumn{2}{c}{ Maximum FeNO } \\
\cline { 2 - 5 } & \multicolumn{1}{c}{$r$} & $P$ value & $r$ & $P$ value \\
\hline Der $p$ & 0.296 & 0.002 & 0.210 & 0.029 \\
Alternaria & -0.140 & 0.268 & -0.147 & 0.243 \\
Cockroach & -0.068 & 0.648 & -0.158 & 0.283 \\
Dog & 0.164 & 0.299 & 0.078 & 0.624 \\
Cat & 0.017 & 0.923 & -0.155 & 0.367
\end{tabular}

FeNO, fractional exhale nitric oxide; ppb, parts per billion; Der $p$, Dermatophagoides pteronyssinus.

with the rate of FeNO higher than $21 \mathrm{ppb}$. By contrast, titers of specific IgE antibody to other indoor allergens did not show significant relationship with maximum FeNO among the serial measurements or the rate of FeNO higher than $21 \mathrm{ppb}$ (Table 5).

\section{Discussion}

In this study on Korean children with atopic asthma, IgE antibodies specific to HDM were more prevalent than those specific to common indoor aeroallergens. Furthermore, HDMspecific IgE antibodies made a major contribution to the increase of total serum IgE. The degree of IgE sensitization to HDM showed a positive relationship with the amount and frequency of FeNO increase, whereas IgE sensitization to other aeroallergens did not. Thus, our data suggest that sensitization to HDM is strongly associated with the development of airway inflammation in the Korean asthmatic population.

HDM allergens have been found in more than $85 \%-90 \%$ of Korean houses and one-third of dust samples from Korean houses contained more than $2 \mathrm{\mu g} / \mathrm{g}$ of HDM allergens ${ }^{17)}$. Particularly, the rate of sensitization to HDM in children suffering from atopic diseases was very high and the proportion of HDM-positive asthmatic children increased with age ${ }^{22)}$. In accordance with these observations, our previous study also demonstrated that HDMs were the most prevalent aeroallergen among subjects with atopic asthma $^{23)}$. Taken together, all these findings imply that HDMs are the most important causative allergens for the development of asthma in Korea.

The high prevalence and titers of HDM-specific IgE antibodies relative to other common indoor aeroallergens found in this study also suggest more important role of HDM as the cause of asthma. Furthermore, specific IgE antibody to HDM made a greater contribution to increase of total IgE than IgE antibodies specific to other indoor aeroallergens. Therefore, IgE antibody produced to HDM provides a possible explanation for the high levels of total IgE found in our study population. The IgE antibody response to HDM may be linked to the probability of developing asthma; Erwin et al. have previously shown that IgE antibodies specific to different allergens can differentially influence both the quantity of total IgE and the prevalence of asthma ${ }^{5}$. Similarly, IgE antibody specific to grass pollens have been suggested to be responsible for increases in total IgE in pollen-sensitized asthmatics during the pollen season ${ }^{24)}$, reflecting the relationship between high exposure to causative allergens and the induction of high titer IgE antibodies.

If sensitization to allergens plays a role in the development of atopic asthma, it is plausible that IgE sensitization to allergens is associated with airway inflammation based on the FeNO level. Thus, it is required to clarify the relative importance of different types of IgE sensitization in airway inflammation by analyzing the relationship between different specific IgE antibody responses and FeNO levels. For this reason, we serially measured FeNO to obtain a longitudinal personalized FeNO profile for each patient. Given that FeNO levels have been shown to be primarily increased in atopic asthma ${ }^{12-14)}$, we limited our study population to atopic individuals. Furthermore, we tried to minimize the effect of ICS on FeNO by obtaining data from patients in which maintenance ICS had been withdrawn. For this purpose, we measured FeNO when patients had been naive to controller treatment for 1 month or more. Asthmatic patients who presented frequent loss of asthma control or were resistant to ICS in low doses were excluded from the study because more frequent and longer duration of treatment reduced chances to measure FeNO levels without the influence of ICS. As a result, study population of this study included milder phenotype of asthmatic patients.

We assessed the FeNO profile of each patient by determining the maximum values among serial measurements and the rates of FeNO higher than the cutoff value ( $>21 \mathrm{ppb}$ ) that had the best combination of sensitivity and specificity for diagnosis of atopic asthma in our previous study ${ }^{25}$. Regardless of the way in which the FeNO profile was analyzed, the degree of IgE sensitization to HDM was associated with both the amount and frequency of FeNO increase. However, these associations were not observed in cases of IgE sensitization to other indoor aeroallergens. This finding, therefore, shows that HDM is a more important causative allergen compared with other indoor aeroallergens in the development of airway inflammation and is consistent with the fact that HDM is the most prevalent allergen in Korea. However, our findings are somewhat different from those reported in previous studies conducted in other countries. In these studies, FeNO was associated with the degree of IgE sensitization to furry animals and mould in asthmatic patients ${ }^{26,27}$. Moreover, in a study from Sweden, HDM sensitization was not related to high $\mathrm{FeNO}^{28}$. We guess that these discrepancies could arise from differences in the type and level of allergen exposure among different countries.

Although they were atopic, 8 patients among our study population had FeNO of $21 \mathrm{ppb}$ or less in all of the longitudinal 
measurements. It is unlikely that FeNO levels in these patients might fluctuate and be accidentally low on all of serial measurements. Instead, persistently low FeNO levels in these patients might be explained by a type of airway pathology unrelated to eosinophilic inflammation. In particular, there is a possibility that this low FeNO group of patients might have predominantly neutrophilic airway inflammation, because marked airway influx of neutrophils in response to allergens has been observed in some atopic asthmatic subjects ${ }^{29,30)}$.

There are several limitations to our study. First, because we did not measure the amount of allergens in dust samples from houses of the study participants, this study could not demonstrate a dose-response relationship between current exposure and airway inflammation based on FeNO measurements. Second, we included only common indoor allergens in the assessment of the relationship between IgE sensitization and airway inflammation in atopic asthma. Thus, the effect of sensitization to outdoor aeroallergens or even food allergens on FeNO was not considered in this study.

In summary, this study shows that HDM-specific IgE antibodies make a major contribution to the high total serum IgE in Korean children with atopic asthma, supporting the association between IgE sensitization to HDM and asthma. Furthermore, the close relationship observed between HDM-specific IgE antibody and longitudinal FeNO indicates the important role of HDM in causing eosinophilic airway inflammation in Korean asthmatic children.

\section{Conflict of interest}

No potential conflict of interest relevant to this article was reported.

\section{Acknowledgments}

This work was supported by the research grant of Chungbuk National University in 2014

\section{References}

1. Platts-Mills T, Leung DY, Schatz M. The role of allergens in asthma. Am Fam Physician 2007;76:675-80.

2. National Asthma Education and Prevention Program, Third Expert Panel on the Diagnosis and Management of Asthma. Expert panel report 3: guidelines for the diagnosis and management of asthma [Internet]. Bethesda (MD): National Heart, Lung, and Blood Institute; [cited 2013 Jul 12]. Available from: http://www.nhlbi. nih.gov/guidelines/asthma/index.htm.

3. Williams SG, Schmidt DK, Redd SC, Storms W; National Asthma Education and Prevention Program. Key clinical activities for quality asthma care. Recommendations of the National Asthma
Education and Prevention Program. MMWR Recomm Rep 2003; 52(RR-6):1-8.

4. Eder W, Ege MJ, von Mutius E. The asthma epidemic. N Engl J Med 2006;355:2226-35.

5. Erwin EA, Ronmark E, Wickens K, Perzanowski MS, Barry D, Lundback B, et al. Contribution of dust mite and cat specific IgE to total IgE: relevance to asthma prevalence. J Allergy Clin Immunol 2007;119:359-65.

6. Asher MI, Montefort S, Bjorksten B, Lai CK, Strachan DP, Weiland SK, et al. Worldwide time trends in the prevalence of symptoms of asthma, allergic rhinoconjunctivitis, and eczema in childhood: ISAAC Phases One and Three repeat multicountry cross-sectional surveys. Lancet 2006;368:733-43.

7. Sunyer J, Jarvis D, Pekkanen J, Chinn S, Janson C, Leynaert B, et al. Geographic variations in the effect of atopy on asthma in the European Community Respiratory Health Study. J Allergy Clin Immunol 2004;114:1033-9.

8. Taylor DR, Pijnenburg MW, Smith AD, De Jongste JC. Exhaled nitric oxide measurements: clinical application and interpretation. Thorax 2006;61:817-27.

9. Jones SL, Kittelson J, Cowan J0, Flannery EM, Hancox RJ, McLachlan CR, et al. The predictive value of exhaled nitric oxide measurements in assessing changes in asthma control. Am J Respir Crit Care Med 2001;164:738-43.

10. de Jongste JC, Carraro S, Hop WC; CHARISM Study Group, Baraldi E. Daily telemonitoring of exhaled nitric oxide and symptoms in the treatment of childhood asthma. Am J Respir Crit Care Med 2009;179:93-7.

11. Stern G, de Jongste J, van der Valk R, Baraldi E, Carraro S, Thamrin $\mathrm{C}$, et al. Fluctuation phenotyping based on daily fraction of exhaled nitric oxide values in asthmatic children. J Allergy Clin Immunol 2011;128:293-300.

12. Crane J, Lampshire P, Wickens K, Epton M, Siebers R, Ingham T, et al. Asthma, atopy and exhaled nitric oxide in a cohort of 6-yr-old New Zealand children. Pediatr Allergy Immunol 2012;23:59-64.

13. Spanier AJ, Hornung RW, Kahn RS, Lierl MB, Lanphear BP. Seasonal variation and environmental predictors of exhaled nitric oxide in children with asthma. Pediatr Pulmonol 2008;43:576-83.

14. Jackson DJ, Virnig CM, Gangnon RE, Evans MD, Roberg KA, Anderson EL, et al. Fractional exhaled nitric oxide measurements are most closely associated with allergic sensitization in schoolage children. J Allergy Clin Immunol 2009;124:949-53.

15. Kharitonov SA, Yates DH, Barnes PJ. Inhaled glucocorticoids decrease nitric oxide in exhaled air of asthmatic patients. Am J Respir Crit Care Med 1996;153:454-7.

16. Silkoff PE, McClean P, Spino M, Erlich L, Slutsky AS, Zamel N. Dose-response relationship and reproducibility of the fall in exhaled nitric oxide after inhaled beclomethasone dipropionate therapy in asthma patients. Chest 2001;119:1322-8.

17. Jeong KY, Park JW, Hong CS. House dust mite allergy in Korea: the most important inhalant allergen in current and future. Allergy Asthma Immunol Res 2012;4:313-25.

18. American Thoracic Society; European Respiratory Society. ATS/ ERS recommendations for standardized procedures for the online and offline measurement of exhaled lower respiratory nitric oxide and nasal nitric oxide, 2005. Am J Respir Crit Care Med 2005; 171:912-30.

19. Miller MR, Hankinson J, Brusasco V, Burgos F, Casaburi R, Coates A, et al. Standardisation of spirometry. Eur Respir J 2005;26:31938.

20. Hankinson JL, Odencrantz JR, Fedan KB. Spirometric reference values from a sample of the general U.S. population. Am J Respir 
Crit Care Med 1999;159:179-87.

21. Crapo RO, Casaburi R, Coates AL, Enright PL, Hankinson JL, Irvin CG, et al. Guidelines for methacholine and exercise challenge testing-1999. This official statement of the American Thoracic Society was adopted by the ATS Board of Directors, July 1999. Am J Respir Crit Care Med 2000;161:309-29.

22. Shin JW, Sue JH, Song TW, Kim KW, Kim ES, Sohn MH, et al. Atopy and house dust mite sensitization as risk factors for asthma in children. Yonsei Med J 2005;46:629-34.

23. Woo SI, Lim JS, Hahn YS. Relationship of indoor aeroallergen specific IgE with total IgE and airway hyperresponsiveness in children with atopic asthma. Pediatr Allergy Respir Dis 2009; 19:47-55.

24. Pollart SM, Reid MJ, Fling JA, Chapman MD, Platts-Mills TA. Epidemiology of emergency room asthma in northern California: association with IgE antibody to ryegrass pollen. J Allergy Clin Immunol 1988;82:224-30.

25. Woo SI, Lee JH, Kim H, Kang JW, Sun YH, Hahn YS. Utility of fractional exhaled nitric oxide $(\mathrm{F}(\mathrm{E}) \mathrm{NO})$ measurements in diagnos- ing asthma. Respir Med 2012;106:1103-9.

26. Malinovschi A, Janson C, Holmkvist T, Norback D, Merilainen P, Hogman M. IgE sensitisation in relation to flow-independent nitric oxide exchange parameters. Respir Res 2006;7:92.

27. Janson C, Kalm-Stephens P, Foucard T, Norback D, Alving K, Nordvall SL. Exhaled nitric oxide levels in school children in relation to IgE sensitisation and window pane condensation. Respir Med 2005;99:1015-21.

28. Patelis A, Janson C, Borres MP, Nordvall L, Alving K, Malinovschi A. Aeroallergen and food IgE sensitization and local and systemic inflammation in asthma. Allergy 2014;69:380-7.

29. Green RH, Brightling CE, Woltmann G, Parker D, Wardlaw AJ, Pavord ID. Analysis of induced sputum in adults with asthma: identification of subgroup with isolated sputum neutrophilia and poor response to inhaled corticosteroids. Thorax 2002;57:875-9.

30. Ndukwu IM, Naureckas ET, Maxwell C, Waldman M, Leff AR. Relationship of cellular transmigration and airway response after allergen challenge. Am J Respir Crit Care Med 1999;160(5 Pt 1): 1516-24. 